\title{
Development of Enhanced Primer Sets for Detection of Norovirus
}

\author{
Byoung-Hwa Kong, ${ }^{1}$ Sung-Geun Lee, ${ }^{2}$ Sang-Ha Han, ${ }^{1}$ Ji-Young Jin, \\ Weon-Hwa Jheong, ${ }^{3}$ and Soon-Young Paik ${ }^{1}$ \\ ${ }^{1}$ Department of Biomedical Sciences, College of Medicine, The Catholic University of Korea, 222 Banpo-daero, \\ Seocho-gu, Seoul 137-701, Republic of Korea \\ ${ }^{2}$ Korea Zoonosis Research Institute, Chonbuk National University, Iksan 570-390, Republic of Korea \\ ${ }^{3}$ Environmental Infrastructure Research Department, National Institute of Environmental Research, \\ Incheon 404-708, Republic of Korea
}

Correspondence should be addressed to Soon-Young Paik; paik@catholic.ac.kr

Received 29 August 2014; Revised 5 November 2014; Accepted 27 November 2014

Academic Editor: Elena Orlova

Copyright (C) 2015 Byoung-Hwa Kong et al. This is an open access article distributed under the Creative Commons Attribution License, which permits unrestricted use, distribution, and reproduction in any medium, provided the original work is properly cited.

\begin{abstract}
Norovirus (NV) is a major viral pathogen that causes nonbacterial acute gastroenteritis and outbreaks of food-borne disease. The genotype of NV most frequently responsible for NV outbreaks is GII.4, which accounts for $60-80 \%$ of cases. Moreover, original and new NV variant types have been continuously emerging, and their emergence is related to the recent global increase in NV infection. In this study, we developed advanced primer sets (NKI-F/R/F2, NKII-F/R/R2) for the detection of NV, including the variant types. The new primer sets were compared with conventional primer sets (GI-F1/R1/F2, SRI-1/2/3, GII-F1/R1/F2, and SRII$1 / 2 / 3)$ to evaluate their efficiency when using clinical and environmental samples. Using reverse transcription polymerase chain reaction (RT-PCR) and seminested PCR, NV GI and GII were detected in 91.7\% (NKI-F/R/F2), 89.3\% (NKII-F/R/R2), 54.2\% (GIF1/R1/F2), 52.5\% (GII-F1/R1/F2), 25.0\% (SRI-1/2/3), and 32.2\% (SRII-1/2/3) of clinical and environmental specimens. Therefore, our primer sets perform better than conventional primer sets in the detection of emerged types of NV and could be used in the future for epidemiological diagnosis of infection with the virus.
\end{abstract}

\section{Introduction}

Norovirus (NV), belonging to family Caliciviridae, is a major cause of acute viral gastroenteritis [1]. Although symptoms, which typically appear between 12 and $48 \mathrm{~h}$, are generally mild and self-limiting, they can be severe in immunocompromised groups such as infants and the elderly $[2,3]$. Viral infection is primarily related to foodborne illness, but person-to-person contact and waterborne outbreaks are also important vehicles for transmission [4-7].

The NV genome is composed of approximately $7.7 \mathrm{~kb}$ of single stranded positive sense RNA (+ssRNA), which includes three open reading frames (ORFs): ORF1, ORF2, and ORF3 [8]. Six nonstructural proteins in a polyprotein are encoded by ORF1, including an RNA-dependent RNA polymerase (RdRp) [9]. ORF2 and ORF3 encode major structural capsid protein (VP1) and minor structural capsid protein
(VP2), respectively [10]. VP1 consists of a shell domain (S) and two protruding $(\mathrm{P})$ domains [11]. The $\mathrm{P} 1$ domain, a protruding flexible hinge region, is located between the $\mathrm{S}$ and $\mathrm{P} 2$ domains [12]. The P2 domain is a hypervariable region that binds to host cell [13]. The stability of VP1 is increased by VP2, which prevents its degradation [14].

$\mathrm{NV}$ is classified into six groups, genogroups I to VI (GI to GVI), based on the amino acid sequences of the RdRp and VP1 [5, 15, 16]. The genogroups GI, GII, and GIV are found in humans [5]. Outbreaks appear more frequently in GI, GII than GIV [17-20]. In particular, GII.4 has emerged continuously every 2-3 years in an evolved form [21]. Consequently, it accounts for $87 \%$ of the NV outbreaks that occur globally [22-24].

In the Republic of Korea, NV GII.4 Sydney type emerged between 2012 and 2013, during which time it accounted for $60.4 \%$ of NV GII.4 diagnoses [25]. Detection of the NV GII 
TABLE 1: Description of NV GI sequences for genetic analysis.

\begin{tabular}{|c|c|c|c|c|c|}
\hline $\begin{array}{l}\text { Accession } \\
\text { number } \\
\text { (GenBank) }\end{array}$ & Genotype & Strain & $\begin{array}{c}\text { Accession } \\
\text { number } \\
\text { (GenBank) }\end{array}$ & Genotype & Strain \\
\hline EU085529 & GI.1 & P774.Delsjo2004/Gothenburg/Sweden & KF039731 & GI.1 & CH4XO533/2009/USA \\
\hline FJ515294 & GI.2 & Leuven/2003/BEL & KF039732 & GI.1 & CHA5A010/2009/USA \\
\hline JN176918 & GI.2 & Roosendaal029/2006/NL & KF039733 & GI.1 & CHA9A004_20110426/2011/USA \\
\hline JN183159 & GI.9 & S48/2008/Lilla & KF039734 & GI.1 & CHA6A014/2009/USA \\
\hline JN183161 & GI.7 & S24/2008/Lilla Edet & KF039735 & GI.1 & CHA3A007/2008/USA \\
\hline JN603244 & GI.3 & S29/2008/Lilla Edet/Sweden & KF039736 & GI.1 & CHA7A011/2010/USA \\
\hline JN603245 & GI.4 & S50/2008/Lilla Edet/Sweden & KF039737 & GI.1 & CHA6A003_20091104/2009/USA \\
\hline JQ388274 & GI.6 & Kingston/ACT160D/2010/AU & KF306212 & GI.2 & Jingzhou/2013401/CHN \\
\hline JQ743331 & GI.4 & 2000 & KF429761 & GI.1 & 8MoIIIL/1972/USA \\
\hline JQ743332 & GI.2 & 1999 & KF429765 & GI.1 & 8W/1968/USA \\
\hline JQ911594 & GI & 10360/2010/VNM & KF429770 & GI.1 & 8McIII/1973/USA \\
\hline JX023285 & GI.1 & 8FIIa/1968/USA & KF429773 & GI.1 & 8CKIIIc/1974/USA \\
\hline KC998959 & GI.6 & TCH-099/USA/2003 & KF429774 & GI.1 & 8UIIIf/1973/USA \\
\hline KF039725 & GI.1 & CHA7A009/2010/USA & KF429783 & GI.1 & 8K/1979/USA \\
\hline KF039726 & GI.1 & /CHA6A003_20091031/2009/USA & KF429789 & GI.1 & $8 \mathrm{MC} / 1978 / \mathrm{USA}$ \\
\hline KF039727 & GI.1 & CHA2A014/2008/USA & KF586507 & GI.9 & CAIQ12110628 \\
\hline KF039728 & GI.1 & CHA2A014/2008/USA & L07418 & & \\
\hline KF039729 & GI.1 & CHA6A007/2010/USA & M87661 & & \\
\hline KF039730 & GI.1 & CHA9A004_20110419/2011/USA & & & \\
\hline
\end{tabular}

strain is difficult with existing RT-PCR primer sets (GIIF1/R1/F2, SRII-1/2/3) because of the continuous variation of the strain $[26,27]$. In addition, GI-F1/R1 primer set does not always have sufficient specificity to detect NV because falsepositive detection commonly occurs [28].

Therefore, the aim of this study was to develop primer sets for efficiently detecting NV GI and GII, including detection of newly emerged strains that could not previously be identified with conventional primer sets. Once new primer sets were developed, we evaluated their efficiency using an RT-PCR assay to test clinical and environmental specimens.

\section{Materials and Methods}

2.1. Collection of Clinical and Environmental Samples. Two sample types, clinical and environmental specimens, were used for detection of NV GI and GII. Eighty-six unknown samples were used for detection of NV GI. They included 22 clinical samples from Gyeonggi Institute of Health Environment (GIHE) that were originally obtained during 2012 and 2013 and 24 clinical and 40 environmental samples from Waterborne Virus Bank (WAVA) originally obtained from 2006 to 2013. To identify NV GII, we used 134 unknown samples that included 35 clinical samples from GIHE, originally collected during 2012 and 2013, and 32 clinical and 67 environmental samples from WAVA, collected from 2006 to 2013.
All stool specimens were collected from patients who suffered from diarrhea caused by acute gastroenteritis. Environmental specimens were collected from groundwater in the Republic of Korea during June and October 2013. All samples were stored at $-80^{\circ} \mathrm{C}$ until use.

2.2. Ethical Clearance. All clinical samples were obtained during the medical treatment of patients with acute gastroenteritis. All patients provided written informed consent, which has been kept on file at the GIHE and WAVA. Human rights were not abused nor were ethical issues encountered during the study. All experimental work and collection of samples were supervised and approved by the Institutional Review Board (IRB) of Songeui Medical Campus, The Catholic University of Korea (approval number MC14SISI0039).

2.3. Primer Design. In order to design new primer sets, 37 sequences of NV GI (Table 1 ) and 52 sequences of NV GII (Table 2) were obtained from NCBI and imported into EditSeq and MegAlign in DNASTAR software (DNASTAR, USA).

We designed 3 candidates for the NV GI primer set and 5 candidates for the NV GII primer set in the conserved regions of ORF 1 and ORF 2. Among them, NKI and NKII (Table 3) which have outstanding efficiency were selected. Inner primers were designed to detect NV from water samples because 
TABLE 2: Description of NV GII sequences for genetic analysis.

\begin{tabular}{|c|c|c|c|c|c|}
\hline $\begin{array}{l}\text { Accession } \\
\text { number } \\
\text { (GenBank) }\end{array}$ & Genotype & Strain & $\begin{array}{c}\text { Accession } \\
\text { number } \\
\text { (GenBank) }\end{array}$ & Genotype & Strain \\
\hline AB447433 & GII.4 & Aormori/2006/JP & JQ320072 & GII.2 & NF2002/USA/2002 \\
\hline AB541319 & GII.4 & Osaka/2007/JP & JX445152 & GII.4 & AlbertaE131/2004/CA \\
\hline AB541321 & GII.4 & Osaka2/2007/JP & JX445153 & GII.4 & AlbertaEI142/2006/CA \\
\hline AB541362 & GII.4 & Toyama5/2008/JP & JX445157 & GII.4 & AlbertaEI513/2006/CA \\
\hline AB543808 & GII.4 & FUMI/2010/JP & JX445159 & GII.4 & AlbertaEI009/2008/CA \\
\hline AB662873 & GII-2 & OC09104/2009/JP & JX445161 & GII.4 & AlbertaEI210/2008/CA \\
\hline AY485642 & GII.4 & Langen 1061/2002/GER & JX445168 & GII.4 & AlbertaEI388/2008/CA \\
\hline AY502023 & GII.4 & Farmington Hills/2002/USA & JX459900 & GII.4 & NSW882J/2011/AU \\
\hline DQ658413 & GII.4 & MD-2004/2004USA & JN899245 & GII.21 & Salisbury150/2011/USA \\
\hline DQ078814 & GII.4 & Hunter504D/2004/AU & JX459907 & GII.4 & NSW3309/2012/AU \\
\hline EF202588 & GII.4 & Toronto SK/2005/CAN & JX459908 & GII.4 & NSW0514/2012/AU \\
\hline EU310927 & GII.4 & TCH186 2002 US & JX846924 & GII.3 & HK71/1978/CHN \\
\hline EF684915 & GII.4 & Shellharbour NSW696T/2006/AUS & JX846925 & GII.2 & KL109/1978/MYS \\
\hline FJ537135 & GII.4 & CHDC2094/1974/US & JX846926 & GII.7 & CHDC3936/1988/USA \\
\hline GQ645366 & GII.4 & NSW3639/2008/AUS & JX989075 & GII.6 & GZ2010-L96/Guangzhou/CHN 2011 \\
\hline GQ845368 & GII.4 & NSW505G 2007 AUS & KC175323 & GII.4 & Hong kong CUHK3630/2012/CHN \\
\hline GQ845369 & GII.4 & Armidale NSW3901/2008/AU & KC464499 & GII.12 & CGMH41/2010/TW \\
\hline GU017907 & GII.14 & 8594/Maizuru/2008/ JPN & KC464505 & GII.2 & CGMH47/2011/TW \\
\hline GU134965 & GII.7 & $1738 / 2009 /$ USA & KC576910 & GII.6 & S9c/1976/SEN \\
\hline GU445325 & GII.4 & New Orleans1805/2009/USA & KC597138 & GII.2 & CHDC2596/1975/USA \\
\hline GU969058 & GII.13 & 8679/Maizuru/2008 JPN & KC597139 & GII.17 & C142/1978/GUF \\
\hline GU980585 & GII.3 & CBNU1/2006/KOR & KC597140 & GII.3 & NIHIC8.1/2011/USA \\
\hline HQ664990 & GII.12 & HS206/2010/USA & KF306213 & GII.3 & Jingzhou/2013402/CHN \\
\hline JN400623 & GII.4 & CGMH25/2010/TW & KF429764 & GII.1 & 21K1/1972/USA \\
\hline JN595867 & GII.4 & Ascension208/2010 & KF429769 & GII.2 & SnowMountRS/1975/USA \\
\hline JN797508 & GII.1 & HawaiiTD/1974/USA & X86557 & GII.4 & Lordsdale virus \\
\hline
\end{tabular}

NV generally presents with a low titer in water [29]. They were constructed based on conserved sites from primer sets NKI-F and NKII-R. We named the inner primers NKI-F2 and NKII$\mathrm{R} 2$ and used them for nested PCR.

2.4. Viral RNA Extraction. Viral RNA was extracted from clinical and environmental specimens with the QIAamp viral RNA extraction kit (Qiagen, Germany) according to the manufacturer's instructions. Each viral RNA sample was eluted with $60 \mu \mathrm{L}$ of elution buffer and stored at $-80^{\circ} \mathrm{C}$ until use in the RT-PCR assay.

2.5. RT-PCR and Seminested PCR. Extracted RNA was amplified by both RT-PCR and seminested PCR in S1000 Thermal Cycler (BIO-RAD, Singapore). In RT-PCR, extracted RNA was reverse-transcribed and amplified using the QIAGEN OneStep RT-PCR Kit (Qiagen, Germany) according to the manufacturer's protocol. The total reaction mixture volume of $25 \mu \mathrm{L}$ contained the following: $5 \times$ QIAGEN OneStep RT-PCR buffer $(5 \mu \mathrm{L}), 20$ pmol primers $(1 \mu \mathrm{L}$ each) (NKI-F/R, NKIIF/R, SRI-1/2, SRII-1/2, GI-F1/R1, and GII-F1/R1), $10 \mathrm{mM}$ dNTP mix $(1 \mu \mathrm{L})$, enzyme mix (reverse transcriptase and Taq polymerase, $1 \mu \mathrm{L})$, extracted viral RNA template $(3 \mu \mathrm{L})$, and RNase-free water (13 $\mu \mathrm{L})$ (Welgene, Republic of Korea). RTPCR conditions were as follows: reverse transcription at $50^{\circ} \mathrm{C}$ for $30 \mathrm{~min}$, initial PCR activation at $95^{\circ} \mathrm{C}$ for $15 \mathrm{~min}, 39$ cycles of denaturation at $94^{\circ} \mathrm{C}$ for $30 \mathrm{~s}$, annealing at each optimal annealing temperature (Tables 4 and 5 ) for $30 \mathrm{~s}$, extension at $72^{\circ} \mathrm{C}$ for $1 \mathrm{~min}$, and a final extension at $72^{\circ} \mathrm{C}$ for $10 \mathrm{~min}$.

For seminested PCR, the RT-PCR product $(3 \mu \mathrm{L})$, 20 pmol primers ( $1 \mu \mathrm{L}$ each) (NKI-F2/R, NKII-F/R2, SRI-2/3, SRII-2/3, GI-F2/R1, and GII-F2/R1), and RNase-free water $(15 \mu \mathrm{L})$ were added to a Maxime PCR PreMix Kit ( $t$-StarTaq) (iNtRON Biotechnology, Republic of Korea). PCR conditions were as follows: initial denaturation at $94^{\circ} \mathrm{C}$ for $2 \mathrm{~min}, 20$ cycles of denaturation at $94^{\circ} \mathrm{C}$ for $20 \mathrm{~s}$, annealing at each optimal annealing temperature (Tables 4 and 5) for $10 \mathrm{~s}$, extension at $72^{\circ} \mathrm{C}$ for $20 \mathrm{~s}$, and a final extension at $72^{\circ} \mathrm{C}$ for $5 \mathrm{~min}$.

2.6. Sequence Analysis of PCR Products. The products of RTPCR and seminested PCR were analyzed using $2 \%$ agarose gel electrophoresis in TAE buffer with DNA SafeStain solution (Lamda Biotech, USA) and were purified in agarose gel with a HiYield Gel/PCR DNA Fragments Extraction Kit (RBC, 
TABLE 3: The nucleotide sequences of NV GI (a) and NV GII (b) strains were compared with sequences of designed primer sets.

(a) GI

\section{NKI primer set}

NKI-F (forward)

\begin{tabular}{|c|c|c|c|c|c|c|c|c|c|c|c|c|c|c|c|c|c|c|c|c|c|}
\hline \multirow{2}{*}{ Primer } & \multicolumn{21}{|c|}{ NKI-F (forward) } \\
\hline & G & $\mathrm{T}$ & A & A & A & $\mathrm{T}$ & G & A & $\mathrm{T}$ & G & A & $\mathrm{T}$ & G & G & $\mathrm{C}$ & G & $\mathrm{T}$ & $\mathrm{C}$ & $\mathrm{T}$ & A & A \\
\hline M87661 (GI) & . & . & . & . & . & . & . & . & . & . & . & . & . & . & . & . & . & . & . & . & . \\
\hline KF039732 (GI.1) & . & . & . & . & . & . & . & . & . & . & . & . & . & . & . & . & . & . & . & . & . \\
\hline KF306212 (GI.2) & . & . & . & . & . & . & . & . & . & . & . & . & . & . & . & . & . & . & . & . & . \\
\hline JN603244 (GI.3) & . & . & . & . & . & . & . & . & . & . & . & . & . & . & . & . & . & . & . & . & . \\
\hline JN603245 (GI.4) & . & . & . & . & . & . & . & . & . & . & . & . & . & . & . & . & . & . & . & . & . \\
\hline JQ388274 (GI.6) & . & . & . & . & . & . & . & . & . & . & . & . & . & . & . & . & . & . & . & . & . \\
\hline JN183161 (GI.7) & . & . & . & . & . & . & . & . & . & . & . & . & . & . & . & . & . & . & . & . & . \\
\hline KF586507 (GI.9) & . & . & . & . & . & . & . & . & . & . & . & . & . & . & . & . & . & . & . & . & . \\
\hline \multirow{2}{*}{ Primer } & \multicolumn{21}{|c|}{ NKI-R (reverse) } \\
\hline & A & $\mathrm{C}$ & $\mathrm{C}$ & $\mathrm{C}$ & A & $\mathrm{D}$ & $\mathrm{C}$ & $\mathrm{C}$ & A & $\mathrm{T}$ & $\mathrm{T}$ & $\mathrm{R}$ & $\mathrm{T}$ & A & $\mathrm{C}$ & A & $\mathrm{T}$ & $\mathrm{Y}$ & $\mathrm{T}$ & G & \\
\hline M87661 (GI) & . & $\cdot$ & . & . & . & . & . & . & . & . & . & . & . & . & . & . & . & . & . & . & 0 \\
\hline KF039732 (GI.1) & . & . & . & . & . & . & . & . & . & . & . & . & . & . & . & . & . & . & . & . & 0 \\
\hline KF306212 (GI.2) & . & . & . & . & . & . & . & . & . & . & . & . & . & . & . & . & . & . & . & . & 0 \\
\hline JN603244 (GI.3) & . & . & . & . & . & G & . & . & . & . & . & . & . & . & . & . & $\cdot$ & . & . & . & 1 \\
\hline JN603245 (GI.4) & . & . & . & . & . & . & . & . & . & . & . & . & . & . & . & . & . & . & . & . & 0 \\
\hline JQ388274 (GI.6) & . & . & . & . & . & . & . & . & . & . & . & . & . & . & . & . & . & . & . & . & 0 \\
\hline JN183161 (GI.7) & . & . & . & . & . & . & . & . & . & . & . & . & . & . & . & . & . & . & . & . & 0 \\
\hline KF586507 (GI.9) & . & . & . & . & . & . & . & . & . & . & . & . & . & . & . & . & . & . & . & . & 0 \\
\hline
\end{tabular}

(b) GII

NKII primer set

Primer NKII-F (forward)

\begin{tabular}{|c|c|c|c|c|c|c|c|c|c|c|c|c|c|c|c|c|c|c|c|c|c|}
\hline (1) & $\mathrm{C}$ & $\mathrm{T}$ & $\mathrm{Y}$ & A & G & G & $\mathrm{C}$ & A & $\mathrm{R}$ & $\mathrm{A}$ & $\mathrm{T}$ & G & $\mathrm{T}$ & $\mathrm{A}$ & $\mathrm{C}$ & $\mathrm{T}$ & G & G & $\mathrm{A}$ & $\mathrm{C}$ & Y \\
\hline X86557 (GII) & . & . & . & . & . & . & . & . & . & . & . & . & . & . & . & . & . & . & . & . & . \\
\hline JN797508 (GII.1) & . & . & . & . & . & $\mathrm{A}$ & . & . & . & . & . & . & . & . & $\mathrm{T}$ & . & . & . & . & . & . \\
\hline KF429769 (GII.2) & . & . & . & . & . & . & . & . & . & . & . & . & . & . & . & . & . & . & . & . & . \\
\hline KF306213 (GII.3) & . & . & . & . & . & A & . & . & . & . & . & . & . & . & $\mathrm{T}$ & . & . & . & . & . & . \\
\hline JX459907 (GII.4) & . & . & . & . & . & . & . & . & . & . & . & . & . & . & . & . & . & . & . & . & . \\
\hline KC464499 (GII.12) & . & . & . & . & . & A & . & . & . & . & . & . & . & . & $\mathrm{T}$ & . & . & . & . & . & . \\
\hline KC597139 (GII.17) & . & . & . & . & . & . & . & . & . & . & . & . & . & . & . & . & . & . & . & . & . \\
\hline JN899245 (GII.21) & . & . & . & . & . & A & . & . & . & . & . & . & . & . & . & . & . & . & . & . & . \\
\hline \multirow{2}{*}{ Primer } & \multicolumn{21}{|c|}{ NKII-R (reverse) } \\
\hline & $\mathrm{T}$ & $\mathrm{C}$ & G & A & $\mathrm{C}$ & G & $\mathrm{C}$ & $\mathrm{C}$ & A & $\mathrm{T}$ & $\mathrm{C}$ & $\mathrm{T}$ & $\mathrm{T}$ & $\mathrm{C}$ & $\mathrm{A}$ & $\mathrm{T}$ & $\mathrm{T}$ & $\mathrm{C}$ & A & $\mathrm{C}$ & \\
\hline X86557 (GII) & . & . & . & . & . & . & . & . & . & . & . & . & . & . & . & $\cdot$ & . & . & . & . & 0 \\
\hline JN797508 (GII.1) & . & . & . & . & . & . & . & . & . & . & . & . & . & . & . & . & . & . & . & . & 0 \\
\hline KF429769 (GII.2) & . & . & . & . & . & . & . & . & . & . & . & . & . & . & . & . & . & . & . & . & 0 \\
\hline KF306213 (GII.3) & . & . & . & . & . & . & . & . & . & . & . & . & . & . & . & . & . & . & . & . & 0 \\
\hline JX459907 (GII.4) & . & . & . & . & . & . & . & . & . & . & . & . & . & . & . & . & . & . & . & . & 0 \\
\hline KC464499 (GII.12) & . & . & . & . & . & . & . & . & . & . & . & . & . & . & . & . & . & . & . & . & 0 \\
\hline KC597139 (GII.17) & . & . & . & . & . & . & . & . & . & . & . & . & . & . & . & . & . & . & . & . & 0 \\
\hline JN899245 (GII.21) & . & . & . & . & . & . & . & . & . & . & . & . & . & . & . & . & . & . & . & . & 0 \\
\hline
\end{tabular}


TABLE 4: Information of NV GI primer sets.

\begin{tabular}{|c|c|c|c|c|c|c|}
\hline Primers & Sequence $\left(5^{\prime}-3^{\prime}\right)^{\mathrm{a}}$ & Location $^{\mathrm{b}}$ & Region & Annealing temperature $\left({ }^{\circ} \mathrm{C}\right)$ & Polarity & Reference \\
\hline NKI-F & GTA AAT GAT GAT GGC GTC TAA & $5354-5373$ & & & + & \\
\hline NKI-R & ACC CAD CCA TTR TAC ATY TG & $5649-5668$ & Capsid & 51 & - & This study \\
\hline NKI-F2 & GAT GGC GTC TAA GGA CGC & $5363-5380$ & & & + & \\
\hline GI-F1 & CTG CCC GAA TTY GTA AAT GAT GAT & $5342-5365$ & & & + & \\
\hline GI-R1 & CCA ACC CAR CCA TTR TAC ATY TG & $5649-5671$ & Capsid & 55 & - & {$[26]$} \\
\hline GI-F2 & ATG ATG ATG GCG TCT AAG GAC GC & $5358-5380$ & & & + & \\
\hline SRI-1 & CCA ACC CAR CCA TTR TAC AT & $5652-5671$ & & & - & \\
\hline SRI-2 & AAA TGA TGA TGG CGT CTA & $5356-5373$ & Capsid & 50 & + & {$[27]$} \\
\hline SRI-3 & AAA AYR TCA CCG GGK GTA T & 5578-5596 & & & - & \\
\hline
\end{tabular}

${ }^{\mathrm{a}}$ The means of alphabet sequence are the following: $Y=C, T ; R=A, G ; K=G, T ; D=A, G, T$.

${ }^{\mathrm{b}}$ Location is based on accession number M87661 (Norwalk virus).

TABLE 5: Information of NV GII primer sets.

\begin{tabular}{|c|c|c|c|c|c|c|}
\hline Primers & Sequence $\left(5^{\prime}-3^{\prime}\right)^{\mathrm{a}}$ & Location $^{\mathrm{b}}$ & Region & Annealing temperature $\left({ }^{\circ} \mathrm{C}\right)$ & Polarity & Reference \\
\hline NKII-F & CTY AGG CAR ATG TAC TGG ACY & $4805-4825$ & & & + & \\
\hline NKII-R & TCG ACG CCA TCT TCA TTC AC & $5081-5100$ & $\operatorname{RdRp}$ & 55 & - & This study \\
\hline NKII-R2 & GGA GCC AGA TTG CGA TCG C & $5060-5078$ & & & - & \\
\hline GII-F1 & GGG AGG GCG ATC GCA ATC T & $5049-5067$ & & & + & \\
\hline GII-R1 & CCR CCI GCA TRI CCR TTR TAC AT & $5367-5389$ & Capsid & 55 & - & {$[26]$} \\
\hline GII-F2 & TTG TGA ATG AAG ATG GCG TCG ART & $5079-5102$ & & & + & \\
\hline SRII-1 & CGC CAT CTT CAT TCA CAA A & $5078-5096$ & & & - & \\
\hline SRII-2 & TWC TCY TTY TAT GGT GAT GAT GA & $4583-4605$ & $\operatorname{RdRp}$ & 50 & + & {$[27]$} \\
\hline SRII-3 & TTW CCA AAC CAA CCW GCT G & $4767-4785$ & & & - & \\
\hline
\end{tabular}

${ }^{\mathrm{a}}$ The means of alphabet sequence are the following: $\mathrm{Y}=\mathrm{C}, \mathrm{T} ; \mathrm{R}=\mathrm{A}, \mathrm{G} ; \mathrm{I}=$ inosine; $\mathrm{W}=\mathrm{A}, \mathrm{T}$.

${ }^{b}$ Location is based on accession number X86557 (Lordsdale virus).

Taiwan). For sequencing, PCR products were sent to Cosmo Genetech (Republic of Korea), and returned sequences were analyzed using the basic local alignment search tool (BLAST) in NCBI.

2.7. Statistical Analysis. An efficiency test of both GI primer sets (GI-F1/R1/F2, SRI-1/2/3, and NKI-F/R/F2) and GII primer sets (GII-F1/R1/F2, SRII-1/2/3, and NKII-F/R/R2) was statistically analyzed using SPSS 20.0 [30].

2.8. Nucleotide Sequence Registration. The NV GI and NV GII sequences that were submitted to GenBank in NCBI (http://www.ncbi.nlm.nih.gov/) were isolated from stool and groundwater samples.

\section{Results}

3.1. Selection of Primer Sets. Collected NV sequences ( 37 from NV GI, 52 from NV GII) were aligned using EditSeq and MegAlign in DNASTAR software. Results showed that conserved sequences were selected in ORF1 and ORF2.

From the 3 and 5 respective candidate NV GI and NV GII primer sets that were evaluated for efficiency using clinical samples, the most efficient primer sets were selected and used in this study (Table 3).
3.2. Detection of NV GI and GII. To evaluate the efficiency of the new primer sets (NKI-F/R/F2, NKII-F/R/R2) designed for this study, we used RT-PCR and compared them to conventional primer sets for NV GI (GI-F1/R1/F2, SRI-1/2/3) and GII (GII-F1/R1/F2, SRII-1/2/3). The ORF1 region was amplified by NKII-F/R/R2 and SRII-1/2/3, while the ORF2 region was amplified by NKI-F/R/F2, SRI-1/2/3, GI-F1/R1/F2, and GII-F1/R1/F2 (Figure 1).

For NV GI, 84 samples were confirmed with GI-F1/R1/F2, SRI-1/2/3, and NKI-F/R/F2 detecting 13, 6, and 22 samples, respectively. For NV GII, 134 samples were identified using GII-F1/R1/F2, SRII-1/2/3, and NKII-F/R/R2 to detect 31, 19, and 53 samples, respectively.

3.3. Comparison of Primer Sets. In total, 83 positive samples were identified, including 50 clinical (18 NV GI, 32 NV GII) and 33 environmental (6 NV GI, 27 NV GII) specimens. The most sensitive primer set for NV GI was NKI-F/R/F2, which detected $22 / 24$ positive samples $(91.7 \%)$. In comparison, the other primers detected 13/24 (54.2\%, GI-F1/R1/F2) and 6/24 (25.0\%, SRI-1/2/3) samples containing NV GI.

In detecting NV GII, the NKII primer set showed a superior diagnostic yield compared to the other sets. NKIIF/R/R2 identified 53/59 (89.3\%) positive NV GII samples, whereas GII-F1/R1/F2 and SRII-1/2/3 identified 31/59 (52.5\%) and 


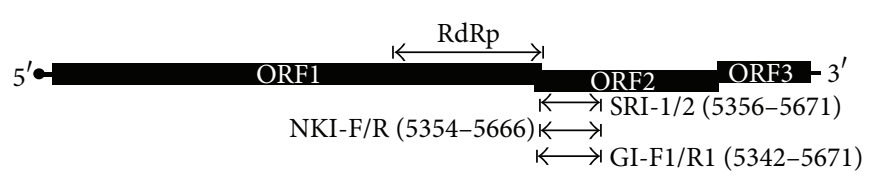

(a)

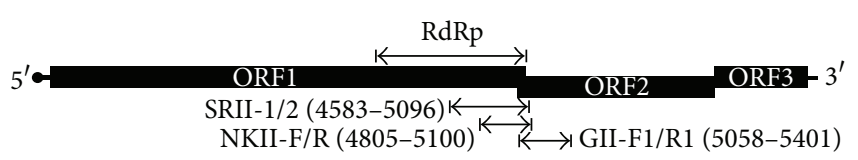

(b)

FIGURE 1: Location of designed primer (NKI F/R, NKII F/R) and conventional primers (SRI-1/2, SRII-1/2, GI-F1/R1, and GII-F1/R1) of NV GI (a) and GII (b).

TABLE 6: Sensitivity of NV GI using each primer set.

\begin{tabular}{|c|c|c|c|}
\hline Positive specimens & NKI F/R/F2 & GI F1/R1/F2 & SRI $1 / 2 / 3$ \\
\hline GI.3 & 3 & 3 & - \\
\hline GI.4 & 6 & 2 & 4 \\
\hline GI.6 & 5 & 4 & 1 \\
\hline GI.8 & 1 & - & 1 \\
\hline GI.15 & 1 & - & - \\
\hline GI & 1 & 1 & - \\
\hline $\begin{array}{l}\text { Clinical samples } \\
(n=18)\end{array}$ & $17(94.4 \%)^{*}$ & $10(58.8 \%)$ & $6(33.3 \%)$ \\
\hline GI.3 & 4 & 3 & - \\
\hline GI.6 & 1 & - & - \\
\hline $\begin{array}{l}\text { Environmental } \\
\text { samples }(n=6)\end{array}$ & $5(83.3 \%)$ & $3(50.0 \%)$ & $0(0 \%)$ \\
\hline Total $(n=24)$ & $22(91.7 \%)$ & $13(54.2 \%)$ & $6(25.0 \%)$ \\
\hline \multicolumn{4}{|c|}{$\begin{array}{l}\text { All } P \text { values }<0.05 \text { are by } t \text {-test except for environmental samples (GI } \\
\text { F1/R1/F2 and NKI F/R/F2). }\end{array}$} \\
\hline
\end{tabular}

$19 / 59$ (32.2\%), respectively. Sensitivity using each primer set is shown in Table 6 (NV GI) and Table 7 (NV GII). SRI-1/2/3 and SRII-1/2/3 were unsuitable for use with environmental samples because positive samples were not detected.

3.4. Sequence Analysis. Results of BLAST sequence analysis indicated that some of the PCR products were amplified using several primers (GI-F1/R1/F2, GII-F1/R1/F2, and SRI-1/2/3) which were shown as false positives of NV, whereas NKIF/R/F2, NKII-F/R/R2, and SRII-1/2/3 did not detect false positives for NV. However, NKI-F/R/F2 and SRI-1/2/3 did detect NV GII in some samples. Where NV GII was detected, it had similar sequences, which were as follows: AB290150 (NKI-F/R/F2), FJ383875 (NKI-F/R/F2, SRI-1/2/3), KF289337 (SRI-1/2/3), and KF509946 (NKI-F/R/F2, SRI-1/2/3).

Genotypes of NV GI.3, GI.4, GI.6, GI.8, and GI.15 and NV GII.2, GII.3, GII.4, GII.6, GII.13, GII.16, GII.17, and GII.21 were identified using GI and GII primer sets, respectively (Tables 6 and 7). Using all primer sets, 17 samples containing the NV GII.4 variant were identified. NKII-F/R/R2, SRII$1 / 2 / 3$, and GII-F1M/R1M/F3M detected NV GII.4 variant type in 16,12 , and 10 samples, respectively.

From positive samples, amplified sequences obtained using NKIF/R/F2 and NKII-F/R/R2 were registered in NCBI. The deposited accession numbers were as follows: KJ742428, KJ742429, KJ742430, KJ742431, KJ742432, KJ742433,
TABLE 7: Sensitivity of NV GII using each primer set.

\begin{tabular}{lccc}
\hline Positive specimens & NKII F/R/R2 & GII F1/R1/F2 & SRII 1/2/3 \\
\hline GII.2 & 2 & 1 & 1 \\
GII.3 & 1 & - & 1 \\
GII.4 & 18 & 11 & 12 \\
GII.6 & 2 & 1 & \\
GII.13 & - & 1 & - \\
GII.16 & 1 & 1 & - \\
GII.17 & 4 & 2 & 4 \\
GII.21 & 1 & - & - \\
GII & 1 & 1 & 1 \\
Clinical samples & $30(93.8 \%)^{*}$ & $18(56.3 \%)$ & $19(59.4 \%)$ \\
$(n=32)$ & 22 & 11 & - \\
\hline GII.4 & 1 & 2 & - \\
GII & $23(85.7 \%)$ & $13(48.1 \%)$ & $0(0 \%)$ \\
Environmental & $53(89.3 \%)$ & $31(52.5 \%)$ & $19(32.2 \%)$ \\
\hline samples $(n=27)$ & & & \\
\hline Total $(n=59)$ & ( $n$ )
\end{tabular}

All $P$ values $<0.05$ are by $t$-test.

Environmental samples were not detected by SRII 1/2/3 primer set.

${ }^{*}$ Percentage is NV detection/NV positive ratio.

KJ742434, KJ742435, KJ742436, KJ742437, KJ742438, KJ742439, KJ742440, KM017944, KM017945, KM017946, KM017947, KM017948, KM017949, KM017950, KM017951, KM017952, KM017953, KM017954, KM017955, KM017956, KM017957, KM017958, and KM017959.

\section{Discussion}

In the USA, estimated 570-800 people die annually from outcomes associated with NV. Outbreaks of the virus occur regularly, and new variant strains are identified worldwide every 2 to 3 years [3, 21, 31, 32]. Methods for detection of NV include RT-PCR, the enzyme-linked immunosorbent assay (ELISA), and transmission electron microscopy (TEM) $[33,34]$. In previous studies, virus concentrations up to $10^{2}$ virus-copies/mL were detected using RT-PCR compared to $10^{5}$ virus-copies $/ \mathrm{mL}$ with other methods [33]. The widespread use of RT-PCR for NV detection can be attributed to its superior sensitivity compared to other methods $[35,36]$. For example, it is the recommended method for detection of $\mathrm{NV}$ in contaminated water, in which $\mathrm{NV}$ commonly exists at $4.91 \times 10^{2}-3.51 \times 10^{3}$ copies/mL [29]. However, in order to minimize outbreaks and prevent potential deaths, improved 
primer sets are required to accurately detect original and variant strains of NV.

It is possible that the primer sets used for detection of NV are different in each laboratory because a standard method for detection has not yet been established [37]. In previously published work, the primer sets GI-F1/R1/F2 and GIIF1/R1/F2, SRI-1/2/3 and SRII-1/2/3 have typically been used to detect NV $[38,39]$. Indeed, GI-F1/R1/F2 and GII-F1/R1/F2 are recommended for detection of NV by the Centers for Disease Control and Prevention's (CDC) of Republic of Korea (http://www.cdc.go.kr/CDC/contents/CdcKrContentView .jsp?cid=18302\&menuIds=HOME001-MNU1175MNU834MNU0839). Lee et al. (2011) used SRI-1/2/3, SRII-1/2/3, GIF1/R1/F2, and GII-F1/R1/F2 primer sets when testing water samples collected in 2008 near groundwater in Republic of Korea [40]. They found that 117 sites were contaminated with NV GI and GII, and the study indicated that NV could more efficiently be detected with GI-F1/R1/F2 (35 samples) and GII-F1/R1/F2 (55 samples) compared to SRI-1/2/3 (27 samples) and SRII-1/2/3 (41 samples) [40]. Similarly, in the present study, the performance of SRI-1/2/3 and SRII-1/2/3 in detection of $\mathrm{NV}$ was inferior to other primer sets. In particular, SRI-1/2/3 and SRII-1/2/3 entirely failed to detect $\mathrm{NV}$ in water. Conversely, the majority of positive NV samples were detected using NKI-F/R/F2 (91.7\%) and NKII-F/R/R2 (89.3\%). We postulate that because the sequences of NKIF/R/F2 and NKII-F/R/R2 were collected from 1968 to 2013, their design contained more conserved sequences in comparison to the GI-F1/R1/F2, GII-F1/R1/F2, SRI, and SRII primer sets and this could explain their superior performance.

NV GII.4 is known to be the most prevalent strain of NV [41], and since 2012 a new variant of NV GII.4 has caused many cases of gastroenteritis [42]. In detecting NV GII.4, an RT-PCR assay using a GII-F1/R1/F2 primer set or another forward primer (Cog2F, F2 FB, GV21) with a GII-F1/R1/F2 reverse primer has typically been used [25, 42-44]. However, these primer sets were designed before 2005 and are not suitable for detection of new NV mutant types that have continuously emerged since, such as the 2012 Sydney strain. Their unsuitability is probably explained by differences in sequence between the primers and the new variant types $[45,46]$.

In this study, NKII-F/R/R2, GII-F1/R1/F2, and SRII were used to detect the NV GII.4 variant. In total, $17 \mathrm{NV}$ GII variant samples were confirmed using NKII-F/R/R2, SRII$1 / 2 / 3$, and GII-F1/R1/F2. They detected 16, 12, and 10 NV GII samples, respectively. The GII-F1/R1/F2 primer set has been widely used for detection of NV GII.4 [42-44, 47]. However, in previous research, the efficiency of this primer set for detecting NV GII.4 was relatively low [25, 41]. Therefore, GIIF1/R1/F2 may be an inappropriate method for detection of the NV GII.4 variant.

\section{Conclusions}

In our study, we showed that the NKI-F/R/F2 and NKIIF/R/R2 primer sets could be important for epidemiological diagnosis of NV in the laboratory because of their superior performance compared to other primer sets. Where contamination with $\mathrm{NV}$ was suspected, these primer sets could be applied to specimens taken from water sample with a low titer or clinical samples with a high titer. Additionally, our newly developed primer sets can be used to detect variant types of NV. Therefore, we recommend the use of NKI-F/R/F2 and NKII-F/R/R2 in future research.

\section{Conflict of Interests}

The authors declare that there is no conflict of interests regarding the publication of this paper.

\section{Acknowledgments}

This study was supported by the National Research Foundation of Korea (NRF-2012R1A2A2A01045078) and Korea Environmental Industry \& Technology Institute (2013000550009).

\section{References}

[1] S. Maritschnik, E. E. Kanitz, E. Simons et al., "A food handlerassociated, foodborne norovirus GII.4 Sydney 2012-outbreak following a wedding dinner, Austria, October 2012," Food and Environmental Virology, vol. 5, no. 4, pp. 220-225, 2013.

[2] S. M. Griffin, N. E. Brinkman, E. J. Hedrick, E. R. Rhodes, and G. S. Fout, "Comparison of nucleic acid extraction and reverse transcription-qPCR approaches for detection of GI and GII noroviruses in drinking water," Journal of Virological Methods, vol. 199, pp. 76-85, 2014.

[3] M. M. Patel, A. J. Hall, J. Vinjé, and U. D. Parashar, "Noroviruses: a comprehensive review," Journal of Clinical Virology, vol. 44, no. 1, pp. 1-8, 2009.

[4] K. Mattison, "Norovirus as a foodborne disease hazard," Advances in Food and Nutrition Research, vol. 62, pp. 1-39, 2011.

[5] D.-P. Zheng, T. Ando, R. L. Fankhauser, R. S. Beard, R. I. Glass, and S. S. Monroe, "Norovirus classification and proposed strain nomenclature," Virology, vol. 346, no. 2, pp. 312-323, 2006.

[6] S. Svraka, E. Duizer, H. Vennema et al., "Etiological role of viruses in outbreaks of acute gastroenteritis in The Netherlands from 1994 through 2005," Journal of Clinical Microbiology, vol. 45, no. 5, pp. 1389-1394, 2007.

[7] L. Barclay, G. W. Park, E. Vega et al., "Infection control for norovirus," Clinical Microbiology and Infection, vol. 20, no. 8, pp. 731-740, 2014.

[8] K. Y. Green, T. Ando, M. S. Balayan et al., "Taxonomy of the caliciviruses," The Journal of Infectious Diseases, vol. 181, supplement 2, pp. S322-S330, 2000.

[9] G. Belliot, S. V. Sosnovtsev, T. Mitra, C. Hammer, M. Garfield, and K. Y. Green, "In vitro proteolytic processing of the MD145 Norovirus ORF1 nonstructural polyprotein yields stable precursors and products similar to those detected in calicivirusinfected cells," Journal of Virology, vol. 77, no. 20, pp. 1095710974, 2003.

[10] M. E. Hardy and M. K. Estes, "Completion of the Norwalk virus genome sequence," Virus Genes, vol. 12, no. 3, pp. 287-290, 1996.

[11] E. F. Donaldson, L. C. Lindesmith, A. D. Lobue, and R. S. Baric, "Viral shape-shifting: norovirus evasion of the human immune system," Nature Reviews Microbiology, vol. 8, no. 3, pp. 231-241, 2010. 
[12] A. Bertolotti-Ciarlet, L. J. White, R. Chen, B. V. V. Prasad, and M. K. Estes, "Structural requirements for the assembly of Norwalk virus-like particles," Journal of Virology, vol. 76, no. 8, pp. 4044-4055, 2002.

[13] B. V. Prasad, M. E. Hardy, T. Dokland, J. Bella, M. G. Rossmann, and M. K. Estes, "X-ray crystallographic structure of the Norwalk virus capsid," Science, vol. 286, no. 5438, pp. 287-290, 1999.

[14] A. Bertolotti-Ciarlet, S. E. Crawford, A. M. Hutson, and M. K. Estes, "The 3 ' end of norwalk virus mRNA contains determinants that regulate the expression and stability of the viral capsid protein vp1: a novel function for the vp2 protein," Journal of Virology, vol. 77, no. 21, pp. 11603-11615, 2003.

[15] T. N. Hoa Tran, E. Trainor, T. Nakagomi, N. A. Cunliffe, and O. Nakagomi, "Molecular epidemiology of noroviruses associated with acute sporadic gastroenteritis in children: global distribution of genogroups, genotypes and GII.4 variants," Journal of Clinical Virology, vol. 56, no. 3, pp. 185-193, 2013.

[16] K. Green, "Caliciviridae: the noroviruses," in Field Virology, D. M. Knipe and P. M. Howley, Eds., pp. 582-608, Lippincott Williams \& Wilkins, Philadelphia, Pa, USA, 6th edition, 2013.

[17] S. Fukuda, Y. Sasaki, S. Takao, and M. Seno, "Recombinant norovirus implicated in gastroenteritis outbreaks in Hiroshima Prefecture, Japan," Journal of Medical Virology, vol. 80, no. 5, pp. 921-928, 2008.

[18] F. C. Tseng, J. S. Leon, J. N. MacCormack, J.-M. Maillard, and C. L. Moe, "Molecular epidemiology of norovirus gastroenteritis outbreaks in North Carolina, United States: 1995-2000," Journal of Medical Virology, vol. 79, no. 1, pp. 84-91, 2007.

[19] T.-H. Han, S.-C. Kim, S.-T. Kim, C.-H. Chung, and J.-Y. Chung, "Detection of norovirus genogroup IV, klassevirus, and pepper mild mottle virus in sewage samples in South Korea," Archives of Virology, vol. 159, no. 3, pp. 457-463, 2014.

[20] Y. Yan, H.-H. Wang, L. Gao et al., "A one-step multiplex realtime RT-PCR assay for rapid and simultaneous detection of human norovirus genogroup I, II and IV,' Journal of Virological Methods, vol. 189, no. 2, pp. 277-282, 2013.

[21] J. J. Siebenga, H. Vennema, B. Renckens et al., "Epochal evolution of GGII.4 norovirus capsid proteins from 1995 to 2006," Journal of Virology, vol. 81, no. 18, pp. 9932-9941, 2007.

[22] A. Polkowska, M. Ronnqvist, and O. Lepisto, "Outbreak of gastroenteritis caused by norovirus GII.4 Sydney variant after a wedding reception at a resort/activity centre, Finland, August 2012," Epidemiology and Infection, vol. 142, no. 9, pp. 1877-1883, 2012.

[23] S. M. Ahmed, B. A. Lopman, and K. Levy, "A systematic review and meta-analysis of the global seasonality of norovirus," PLoS ONE, vol. 8, no. 10, Article ID e75922, 2013.

[24] J. A. Marshall and L. D. Bruggink, "The dynamics of norovirus outbreak epidemics: recent insights," International Journal of Environmental Research and Public Health, vol. 8, no. 4, pp. 11411149, 2011.

[25] H. S. Kim, J. Hyun, H.-S. Kim, J.-S. Kim, W. Song, and K. M. Lee, "Emergence of GII.4 Sydney norovirus in South Korea during the winter of 2012-2013," Journal of Microbiology and Biotechnology, vol. 23, no. 11, pp. 1641-1643, 2013.

[26] S. H. Kim, D. S. Cheon, J. H. Kim et al., "Outbreaks of gastroenteritis that occurred during school excursions in Korea were associated with several waterborne strains of norovirus," Journal of Clinical Microbiology, vol. 43, no. 9, pp. 4836-4839, 2005.

[27] D. Häfliger, M. Gilgen, J. Lüthy, and P. Hübner, "Seminested RTPCR systems for small round structured viruses and detection of enteric viruses in seafood," International Journal of Food Microbiology, vol. 37, no. 1, pp. 27-36, 1997.

[28] E. Wollants and M. van Ranst, "Detection of false positives with a commonly used Norovirus RT-PCR primer set," Journal of Clinical Virology, vol. 56, no. 1, pp. 84-85, 2013.

[29] L. Kittigul, A. Panjangampatthana, K. Pombubpa et al., "Detection and genetic characterization of norovirus in environmental water samples in Thailand," The Southeast Asian Journal of Tropical Medicine and Public Health, vol. 43, no. 2, pp. 323-332, 2012.

[30] H. S. Lee and J. H. Lim, SPSS 20.0 Manual, Jiphyunjae, Seoul, Republic of Korea, 2013.

[31] A. J. Hall, B. A. Lopman, D. C. Payne et al., "Norovirus disease in the united states," Emerging Infectious Diseases, vol. 19, no. 8, pp. 1198-1205, 2013.

[32] L. Barclay, G. W. Park, E. Vega et al., "Infection control for norovirus," Clinical Microbiology and Infection, vol. 20, no. 8, pp. 731-740, 2014.

[33] H. F. Rabenau, M. Stürmer, S. Buxbaum, A. Walczok, W. Preiser, and H. W. Doerr, "Laboratory diagnosis of norovirus: which method is the best?" Intervirology, vol. 46, no. 4, pp. 232-238, 2003.

[34] J. Vinjé, "Advances in laboratory methods for detection and typing of norovirus," Journal of Clinical Microbiology, 2014.

[35] E. de Bruin, E. Duizer, H. Vennema, and M. P. G. Koopmans, "Diagnosis of Norovirus outbreaks by commercial ELISA or RT-PCR," Journal of Virological Methods, vol. 137, no. 2, pp. 259264, 2006.

[36] M. Swellam, M. S. Mahmoud, and A. A.-F. Ali, "Diagnosis of hepatitis $C$ virus infection by enzyme-linked immunosorbent assay and reverse transcriptase-nested polymerase chain reaction: a comparative evaluation," IUBMB Life, vol. 63, no. 6, pp. 430-434, 2011.

[37] E. Guévremont, J. Brassard, A. Houde, C. Simard, and Y.-L. Trottier, "Development of an extraction and concentration procedure and comparison of RT-PCR primer systems for the detection of hepatitis A virus and norovirus GII in green onions," Journal of Virological Methods, vol. 134, no. 1-2, pp. 130135, 2006.

[38] I. L. A. Boxman, J. J. H. C. Tilburg, N. A. J. M. Te Loeke et al., "Detection of noroviruses in shellfish in the Netherlands," International Journal of Food Microbiology, vol. 108, no. 3, pp. 391396, 2006.

[39] H. K. Joung, S. H. Han, S.-J. Park et al., "Nationwide surveillance for pathogenic microorganisms in groundwater near carcass burials constructed in South Korea in 2010," International Journal of Environmental Research and Public Health, vol. 10, no. 12, pp. 7126-7143, 2013.

[40] S.-G. Lee, W.-H. Jheong, C.-I. Suh et al., "Nationwide groundwater surveillance of noroviruses in South Korea, 2008," Applied and Environmental Microbiology, vol. 77, no. 4, pp. 1466-1474, 2011.

[41] J.-G. Fu, J. Ai, X. Qi, J. Zhang, F.-Y. Tang, and Y.-F. Zhu, "Emergence of two novel norovirus genotype II.4 variants associated with viral gastroenteritis in China," Journal of Medical Virology, vol. 86, no. 7, pp. 1226-1234, 2014.

[42] H. Mai, M. Jin, X. Guo et al., "Clinical and epidemiologic characteristics of norovirus GII.4 sydney during winter 2012-13 in beijing, china following its global emergence," PLoS ONE, vol. 8, no. 8, Article ID e71483, 2013. 
[43] A. Thongprachum, W. Chan-it, P. Khamrin et al., "Molecular epidemiology of norovirus associated with gastroenteritis and emergence of norovirus GII.4 variant 2012 in Japanese pediatric patients," Infection, Genetics and Evolution, vol. 23, pp. 65-73, 2014.

[44] J. Fonager, S. Barzinci, and T. K. Fischer, "Emergence of a new recombinant Sydney 2012 norovirus variant in Denmark, 26 December 2012 to 22 March 2013," Eurosurveillance, vol. 18, no. 25, 2013.

[45] J.-S. Eden, M. M. Tanaka, M. F. Boni, W. D. Rawlinson, and P. A. White, "Recombination within the pandemic norovirus GII.4 lineage," Journal of Virology, vol. 87, no. 11, pp. 6270-6282, 2013.

[46] V. Martella, M. C. Medici, S. de Grazia et al., "Evidence for recombination between pandemic GII.4 norovirus strains New Orleans 2009 and Sydney 2012," Journal of Clinical Microbiology, vol. 51, no. 11, pp. 3855-3857, 2013.

[47] M. C. W. Chan, T. F. Leung, A. K. Kwok, N. Lee, and P. K. S. Chan, "Characteristics of patients infected with norovirus GII.4 Sydney 2012, Hong Kong, China," Emerging Infectious Diseases, vol. 20, no. 4, pp. 558-661, 2014. 

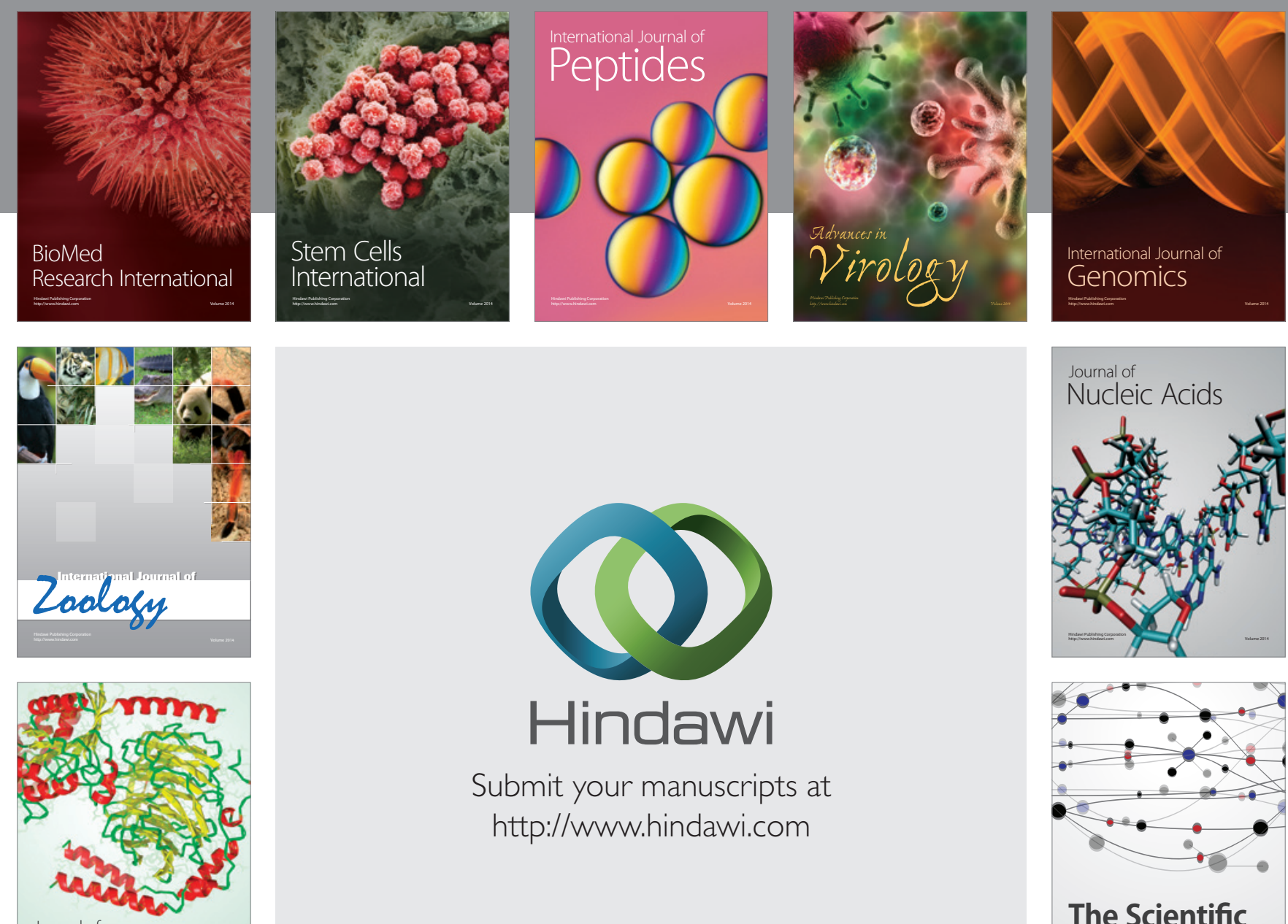

Submit your manuscripts at

http://www.hindawi.com

Journal of
Signal Transduction
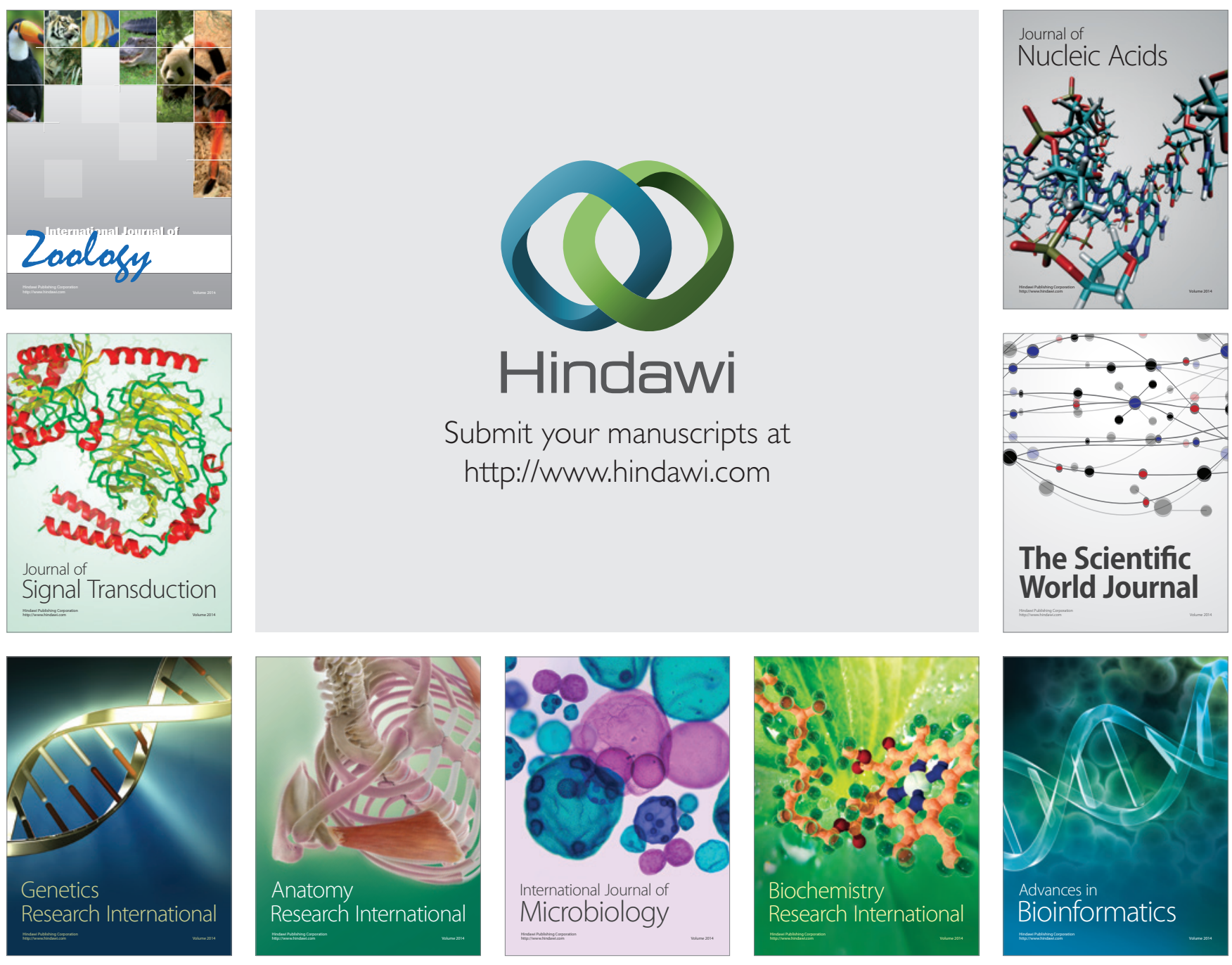

The Scientific World Journal
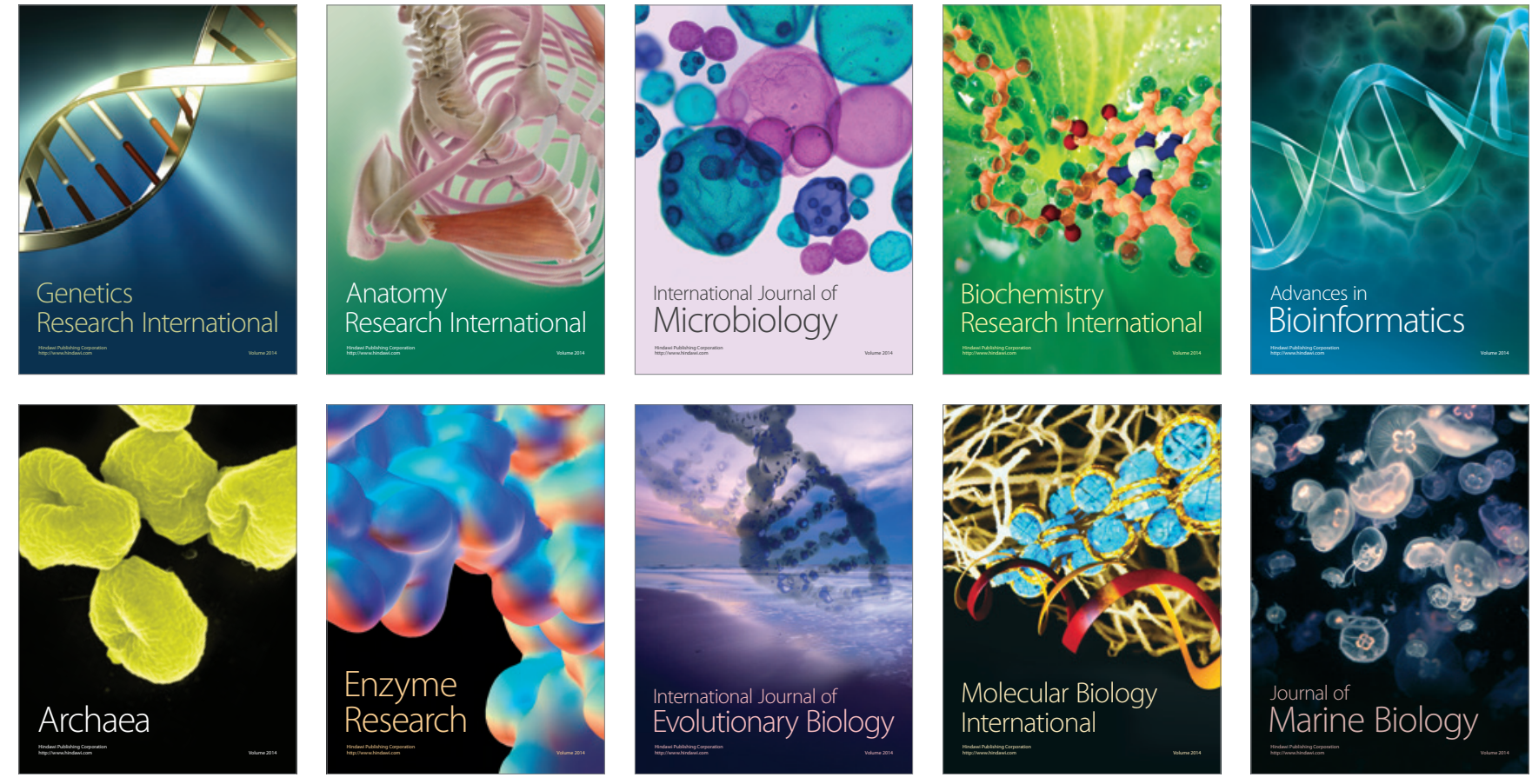